\title{
A Smart Monitoring of a Water Quality Detector System
}

\author{
S. I. Samsudin, S.I.M. Salim, K. Osman, S. F. Sulaiman, M. I. A. Sabri \\ Centre of Telecommunication Research and Innovation, Faculty of Electronics and Computer Engineering, \\ Universiti Teknikal Malaysia Melaka, Hang Tuah Jaya, 76100 Durian Tunggal, Melaka, Malaysia
}

\begin{tabular}{l}
\hline \hline Article Info \\
\hline Article history: \\
Received Jan 17, 2018 \\
Revised Mar 28, 2018 \\
Accepted Apr 12, 2018
\end{tabular}

\section{Keywords:}

IoT

$\mathrm{pH}$

Turbidity

Water monitoring

\begin{abstract}
The importance to monitor the water quality level is undeniable due to significant impact to human health and ecosystem. The project aims to develop a wireless water quality monitoring system that aids in continuous measurements of water conditions based on $\mathrm{pH}$ and turbidity measurements. These two sensors are connected to microprocessor and transmitted to the database by using a Wi-Fi module as a bridge. The developed system was successfully detect both the $\mathrm{pH}$ and turbidity values hence updating in IoT platform. Based on the results obtained, the test water sample can be classified to class IIB which is suitable for water recreational used body contact. Overall, the developed system offers fast and easy monitoring of $\mathrm{pH}$ and turbidity levels with IoT application for continuous maintenance of clean water. The work is just concern on the physical water parameters hence further extend to chemical parameter for verifying a better result in measuring the WQI value.
\end{abstract}

Copyright (C) 2018 Institute of Advanced Engineering and Science. All rights reserved.

\section{Corresponding Author:}

Sharatul Izah Samsudin,

Department of Electrical and Computer Engineering,

Centre of Telecommunication Research and Innovation,

Faculty of Electronics and Computer Engineering,

Universiti Teknikal Malaysia Melaka, Hang Tuah Jaya, 76100 Durian Tunggal, Melaka, Malaysia.

Email: sharatul@utem.edu.my

\section{INTRODUCTION}

The water quality index (WQI) is always used in order to justify or classify the level of water quality. WQI acts as mean indication of water quality measurement through the determination of physico-chemical parameters of surface water [1]. It is important to measure the level of the water quality before consuming or safe use for other purposes. For water quality classification, several physical, biological and chemical parameters that have significant impact on the water quality have to be identified. The measurements obtained are then compared to water quality standards of Malaysia.

However, water samples are normally collected at regular periods continued by laboratory analysis thus ask for larger time consumption. Besides, there are certain chemical and biological processes such as oxidation-reduction potential that require for on-site measurement to ensure accuracy and other aspects to be considered as discussed in [2]. Therefore, online water quality monitoring systems which potential to deliver continuous data is highly demanded. The objective of this work is to develop a low-cos wireless water quality monitoring system that aids in continuous measurements of water conditions.

The Department of Environment (DOE) water quality parameters and index including its classes is presented in Table 1. According to Table 1, there are six parameters to be measured for water quality control which are Ammoniacal Nitrogen, Biochemical Oxygen Demand (BOD), Chemical Oxygen Demand (COD), Dissolved Oxygen (DO), pH, and Total Suspended Solid (TSS) [3]. However, since this is an initial study of water project, two parameters of DOE stated which are $\mathrm{pH}$ and total suspended solid (tss) are just emphasized. 
Table 1 . DOE water quality parameters and index including its classes

\begin{tabular}{|c|c|c|c|c|c|c|}
\hline \multirow{2}{*}{ Parameter } & \multirow{2}{*}{ Unit } & \multicolumn{5}{|c|}{ Class } \\
\hline & & $\mathrm{I}$ & II & III & IV & $\mathrm{V}$ \\
\hline \multirow{6}{*}{$\begin{array}{l}\text { Ammoniacal Nitrogen } \\
\text { Biochemical Oxygen } \\
\text { Demand } \\
\text { Dissolve Oxygen } \\
\text { pH } \\
\text { Total Suspended Solid } \\
\text { Water Quality Index } \\
\text { (WQI) }\end{array}$} & $\mathrm{mg} / 1$ & $<0.1$ & $0.1-0.3$ & $0.3-0.9$ & $0.9-2.7$ & $>2.7$ \\
\hline & $\mathrm{mg} / 1$ & $<1$ & $1-3$ & $3-6$ & $6-12$ & $>12$ \\
\hline & $\mathrm{mg} / 1$ & $<10$ & $10-25$ & $25-50$ & $50-100$ & $>100$ \\
\hline & 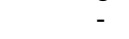 & $>7$ & $5-7$ & $3-5$ & $1-3$ & $<1$ \\
\hline & $\mathrm{mg} / 1$ & $>7$ & $6-7$ & $5-6$ & $<5$ & $>5$ \\
\hline & . & $<25$ & $25-50$ & $50-150$ & $150-300$ & $>300$ \\
\hline Class & \multicolumn{6}{|c|}{ Uses } \\
\hline & \multicolumn{6}{|c|}{ Conservation of natural environment. } \\
\hline Class I & \multicolumn{6}{|c|}{$\begin{array}{l}\text { Water supply I- Practically no treatment necessary. } \\
\text { Fishery I- Very sensitive aquatic species. }\end{array}$} \\
\hline Class IIA & \multicolumn{6}{|c|}{ Water supply II- Conventional treatment. } \\
\hline Class IIB & \multicolumn{6}{|c|}{ Recreational use body contact. } \\
\hline & \multicolumn{6}{|c|}{ Water supply III- Extensive treatment required. } \\
\hline Class III & \multicolumn{6}{|c|}{$\begin{array}{l}\text { Fishery III- Common of economic value and tolerant species; } \\
\text { livestock drinking. }\end{array}$} \\
\hline Class IV & \multicolumn{6}{|l|}{ Irrigation } \\
\hline Class V & \multicolumn{6}{|c|}{ None of above. } \\
\hline
\end{tabular}

There are various studies of water quality monitoring system such discussed in [4] and [5]. In [4], a system which enables remote probing and real-time monitoring of the water quality parameters and enables observation of current and historical water quality status are developed. A ZigBee based on wiresless sensor network monitoring is applied. [5] implements water monitoring system which cover the analyses of $\mathrm{pH}$, conductivity, dissolved oxygen and temperature's level. Sounds an alarm will be triggered if there is a water contamination or change in water quality. The parameters are measured with off-the shelf sensors and data is sent to a base station via GPRS. Meanwhile, the aim of [2] is to develop a low-cost wireless water quality monitoring system that aids in continuous measurements of water conditions. A prototype sensor as one component of the Autonomous Live Animal Response Monitor (ALARM) has been developed. The system measure temperature, light intensity, $\mathrm{pH}$, electrical conductivity, total dissolved solids, salinity, dissolved oxygen and oxidation reduction potential as the parameters. On top of that, several previous works has been reviewed in terms of hardware and software selection such as microcontroller, $\mathrm{pH}$ and turbidity sensors.

Based on [6], the microcontroller used for the system is a Raspberry Pi (RPi) model B. This model has $256 \mathrm{Mb}$ of RAM memory and $700 \mathrm{MHz}$ processor and its architecture allows the development of several, different embedded system projects through the GPIO pins. This makes less demanding the collaboration with other equipment. The RPi is a very low-cost computer, with the compact size which supports Unix platforms. The difference for the proposed project is the used of WeMos D1 R2. The WeMos D1 R2 have almost same layout with the Arduino UNO except the number of analog I/O pins provided. The Arduino UNO offers six analog I/O pins while WeMos D1 only provided with one analog I/O pin. On the bright side, the WeMos is already embedded with a Wi-Fi module ESP8266 and cheaper compared to Arduino UNO. With Wi-fi module, the project is specifically use the ESP-12F that was embedded on the WeMos D1 R2.

In terms of $\mathrm{pH}$ sensor, [2] uses $\mathrm{pH}$ sensor from Phidgets. It measures the full $\mathrm{pH}$ range from 0 to 14 and operates in the temperature range of $0 \circ-80^{\circ} \mathrm{C}$. The Phidgets also supplies adaptor to convert $\mathrm{BNC}$ to analog voltage after sensing. Using this adaptor, the $\mathrm{pH}$ sensor data is acquired at Arduino analog pin. Meanwhile, [7] measures $\mathrm{pH}$ through the use of a conventional glass electrode with a reference electrode setup, the other is using an Ion-Selective-Field-Effect-Transistor (ISFET). The $\mathrm{pH}$ sensor will consist of a conventional glass electrode as these electrodes are more reliable and economical for long term monitoring. However, this project will use an analog $\mathrm{pH}$ sensor SKU:SEN0161 by DFRobot. It also measure the $\mathrm{pH}$ range from 0 to 14 and operates in the temperature range from $0^{\circ} \mathrm{C}-60^{\circ} \mathrm{C}$. It has an LED which works as the Power Indicator, a BNC connector and PH2.0 sensor interface.

Meanwhile, turbidity sensor detects suspended particles in water by measuring the light transmittance and scattering rate which changes with the amount of total suspended solids (tss) in water. As the tss increases, the liquid turbidity level increases. [2] uses a light sensor to measure water turbidity which operate at $3.3 \mathrm{~V}$ and $5 \mathrm{~V}$. The range of light intensity can be measured from $0-1000 \mathrm{~lx}$ and sensor output is of nonratiometric type. However, the project will use a turbidity sensor SKU: SEN0189 by DFRobot. Other research work studies the water monitoring dan control can be further review in [8-10]. 
The paper is organized as follows. The project implementation is explained in Section 2 while the result and analysis obtained is discussed in Section 3. The conclusion of the project drawn is next presented in Section 4.

\section{RESEARCH METHOD}

The implementation of this project can be divided into two major sections; hardware and software implementation.

\subsection{Hardware Implementation}

The hardware involves are microcontroller, $\mathrm{pH}$ and turbidity sensors and Wi-Fi module. In general, the microcontroller processes the data taken by $\mathrm{pH}$ and turbidity sensors hence sending the data to the database by using the Wi-Fi module as a bridge.

\subsubsection{Microcontroller}

Figure 1 shows a WeMos D1 R2 Arduino Compatible layout or commonly referred as WeMos D1. As discussed, WeMos D1 microcontroller has the same layout with Arduino UNO except a Wi-Fi module embedded onto the board.

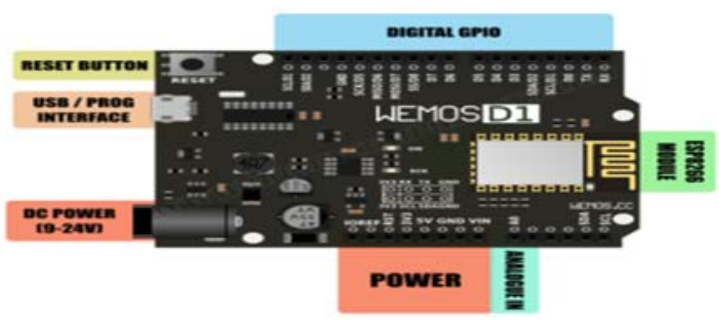

Figure 1. WeMos D1 layout

\subsection{2. pH and turbidity sensors}

Figure 2 shows an analog pH sensor SKU:SEN0161 by DFRobot. The sensor is connected to the first WeMos D1 analog pin, A0 as shown in Figure 2.

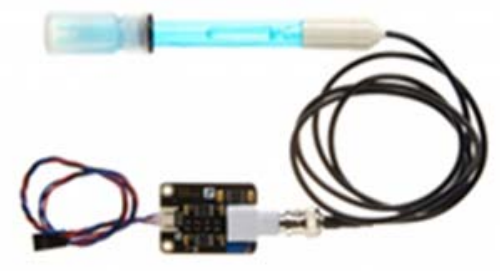

(a) A pH sensor

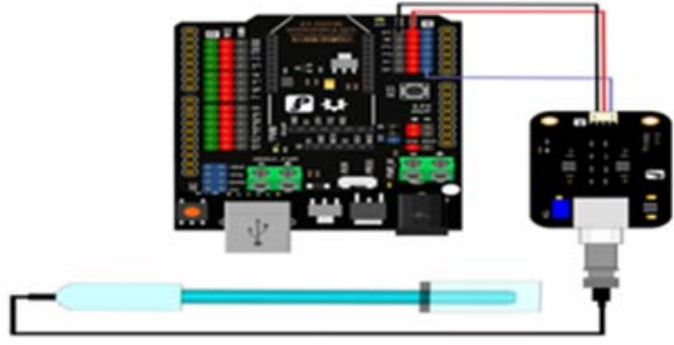

(b) $\mathrm{pH}$ sensor connection to microprocessor board

Figure 2. A pH sensor

Turbidity sensor SKU: SEN0189 by DFRobot is shown in Figure 3. This sensor provides analog and digital signal output modes while the threshold is adjustable when in digital signal mode. This sensor is next connected to the second WeMos D1 analog pin, A0. 


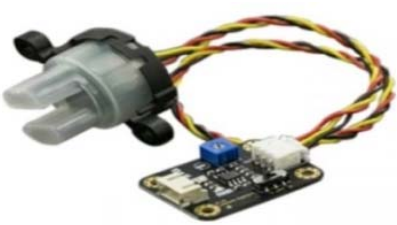

(a) A turbidity sensor

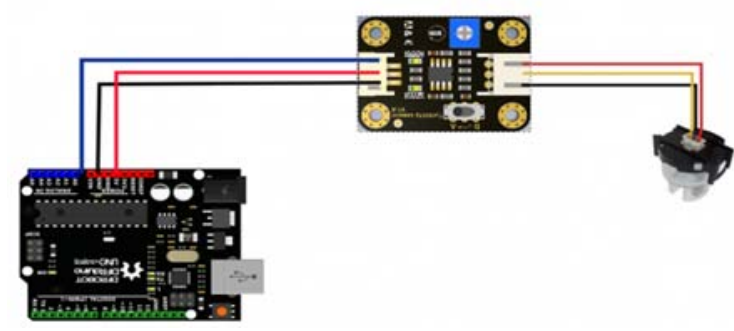

(b) Turbidity sensor connection to the microprocessor board

Figure 3. Turbidity sensor

\subsubsection{Wi-Fi module}

The ESP8266 module type ESP-12F is used as a Wi-Fi Module as shown in Figure 4. This Wi-Fi Module is a self-contained SOC with integrated TCP/IP protocol stack that can give any microcontroller access to Wi-Fi network. The ESP8266 is capable of either hosting an application or offloading all Wi-Fi networking functions from another application processor. Each ESP8266 module comes pre-programmed with an AT command set firmware, which can simply plug-and-play to Arduino device and get about as much Wi-Fi-ability as a Wi-Fi Shield offers.

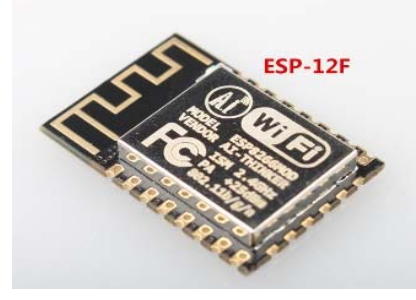

(a) ESP-12F module

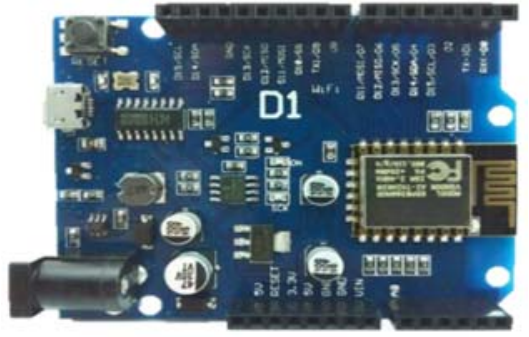

(b) ESP-12F embedded on microcontroller board WeMos D1

Figure 4. ESP-12F module

\subsection{Software Implementation}

Basically, the hardware was programmed by using Arduino IDE. The open-source Arduino Software (IDE) makes it easy to write code and upload it to the board. It runs on Windows, Mac OS X, and Linux. The environment is written in Java and based on Processing and another open-source software. This software can be used with any Arduino compatible board such as WeMos D1 R2.

The data collected were next archived in online database, Ubidots. Ubidots are specializing in hardware and software development for IoT projects. It is an open source software that facilitates developers to easily capture sensor data and turn it into useful information. The Ubidots platform can be used to send data to the cloud from any internet-enabled device by configuring actions and alerts based on the real-time data and disengage the value of data through visual tools.

Finally, the data was displayed at webpage created by open software, Wix. The wix.com is one of the most popular HTML5 website builders (cloud-based web development). The Wix introduced a mobile editor that the size or the style better in mobile viewing. The concept of building the websites by using their online drag and drop tools is very easy to use. The block diagram of developed complete system is presented in Figure 5. The pH sensor and turbidity sensor were connected to the Arduino. The Arduino will then process the data and send it to database through Wi-Fi module ESP8266. The user will be able to receive the updated data hence allowing for water quality level classification based on DOE measurement.

The $\mathrm{pH}$ and turbidity data were recorded in both offline and online measurement. For offline action, the data were recorded for five days and maintained to be collected on $5 \mathrm{pm}$ to $6 \mathrm{pm}$. The data were next continuously collected by online measurement in IoT platform. 


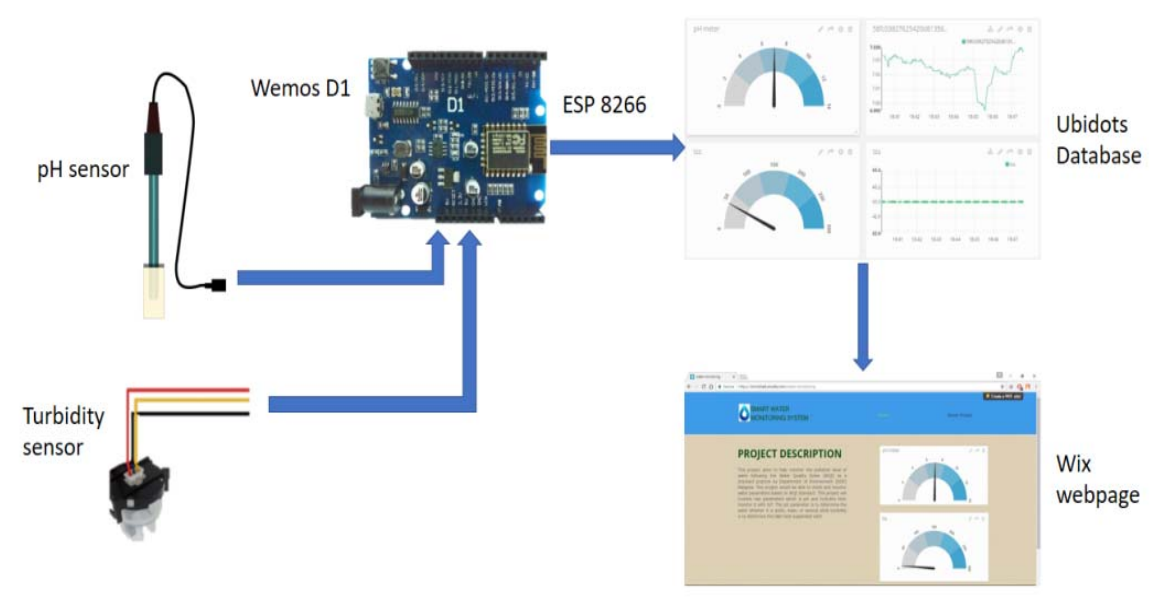

Figure 5. A block diagram of a complete system

\section{RESULTS AND ANALYSIS}

A complete system of Smart Monitoring Water Quality Detector is presented in Figure 6. As observed, the system is floated dan tested at Tasik UTeM.

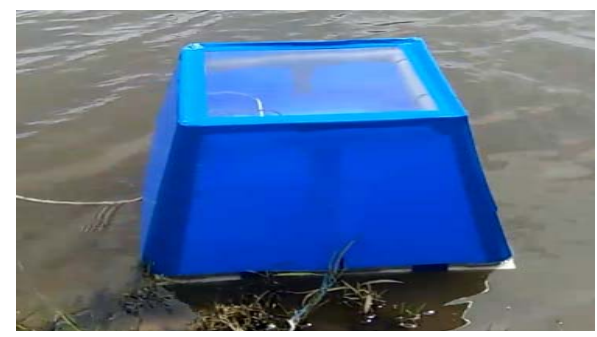

Figure 6. Smart Monitoring Water Quality Detector System

\subsection{Experiment Procedure of $\mathrm{pH}$ and Turbidity Sensors}

Upon completion, the system has been tested and calibrated to achieve stability and accuracy of the measurements. The result of $\mathrm{pH}$ troubleshoots's are discussed:

\subsection{1 pH sensor}

The $\mathrm{pH}$ experiment is divided into three categories which are alkaline, acidic, or neutral. These experiments will be conducted in same order but with different test $\mathrm{pH}$ solution. The $\mathrm{pH}$ sensor is dip into the $\mathrm{pH}$ solutions while the reading is recorded. To ensure the reading accuracy, adjustment the "Offset" value in the codes has been done to \pm 0.10 . Table 2-4 show the results of alkaline, acidic and neutral test $\mathrm{pH}$ solution using the modeled developed.

According to Table 2-4, it was proved that the applied $\mathrm{pH}$ sensor is accurately read the $\mathrm{pH}$ level; with the differences between the actual reading and the experimental value is not more than $0.9 \%$ on average of percentage error. It is noticed that the $\mathrm{pH}$ electrode must be initially washed with distilled water for each measurement of $\mathrm{pH}$ test solution for a reliable reading.

Table 2. Results of acidic experiment

\begin{tabular}{cc}
\hline Test $\mathrm{pH}$ Solution $(\mathrm{pH})$ & Experimental Value $(\mathrm{pH})$ \\
\hline 4.00 & 4.02 \\
4.00 & 4.01 \\
4.00 & 4.01 \\
4.00 & 4.00 \\
4.00 & 4.01 \\
& $\overline{\mathrm{x}}=4.01$ \\
\hline
\end{tabular}


Table 3. Results of neutral experiment of troubleshooting

\begin{tabular}{cc}
\hline Test $\mathrm{pH}$ Solution $(\mathrm{pH})$ & Experimental Value $(\mathrm{pH})$ \\
\hline 6.860 & 6.96 \\
6.860 & 6.95 \\
6.860 & 6.94 \\
6.860 & 6.94 \\
6.860 & 6.94 \\
& $\mathrm{x}=6.946$ \\
\hline
\end{tabular}

Table 4. Results of alkaline experiment of troubleshooting

\begin{tabular}{cc}
\hline Test $\mathrm{pH}$ Solution $(\mathrm{pH})$ & Experimental Value $(\mathrm{pH})$ \\
\hline 9.180 & 9.070 \\
9.180 & 9.070 \\
9.180 & 9.080 \\
9.180 & 9.060 \\
9.180 & 9.060 \\
& $\overline{\mathrm{x}}=9.068$ \\
\hline
\end{tabular}

\subsubsection{Turbidity sensor}

The system was tested with filtered water that has actual reading of 0.1. Again, adjustment of "Offset" value in the codes has been done to \pm 0.10 to ensure the reading accuracy.

\subsection{System Results}

The system is next setup at "Tasik UTeM". Two assessments have been done where the data were collected in offline and online measurements.

\subsubsection{Offline measurements}

The data of offline measuremet was recorded for five days in two weeks; and maintained to be collected at every $5 \mathrm{pm}$ to $6 \mathrm{pm}$. The results obtained are shown in Figure 7.
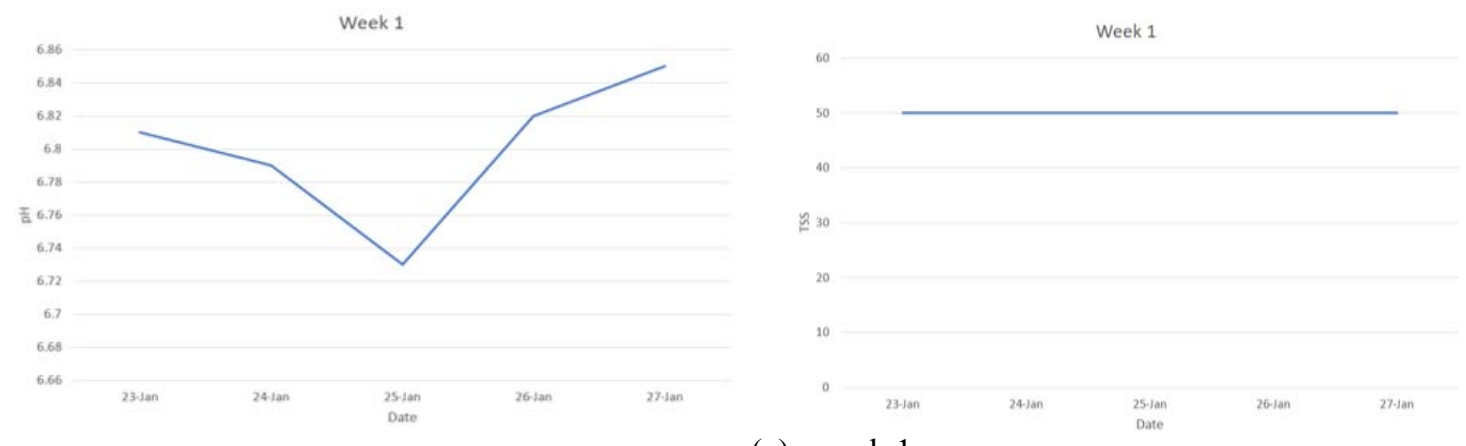

(a) week 1
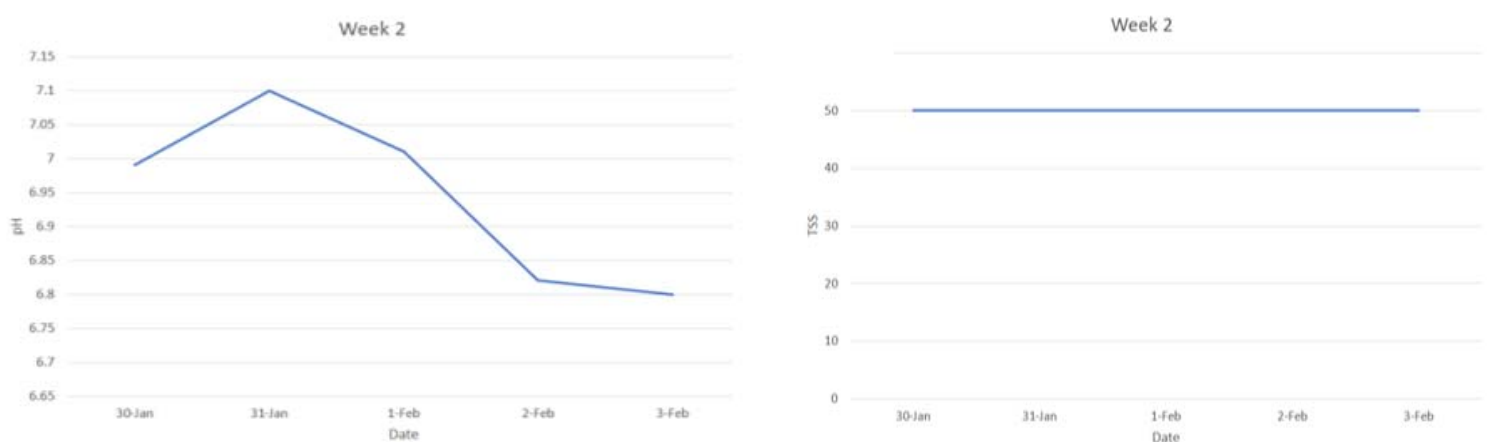

(b) week 2

Figure 7. Offline measurement of $\mathrm{pH}$ and turbidity levels 


\subsubsection{Online measurements}

The data of online measurement was collected with the function of the IoT application. The system was connected to the Service Set Identifier (SSID) provided and transmitted the data to the online database, Ubidots. The Figure 8 shows a result collected by the online database, Ubidots.

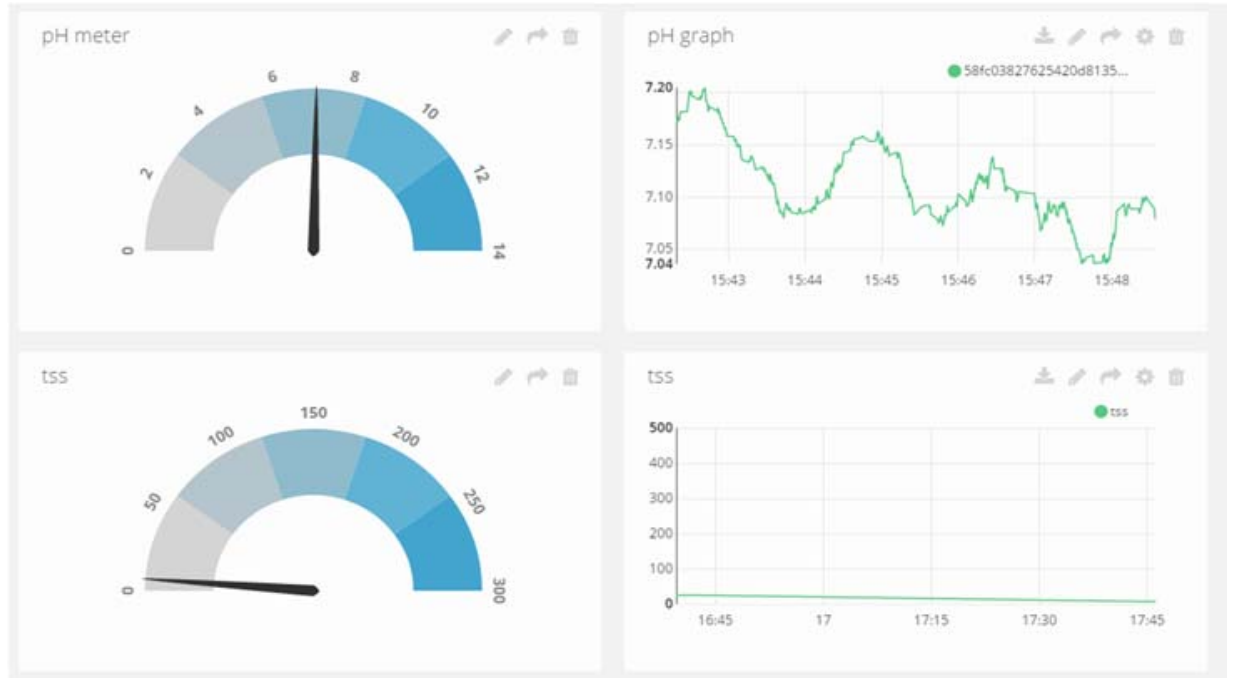

Figure 8. $\mathrm{pH}$ and tss results on Ubidots platform

The $\mathrm{pH}$ results indicate that the tested water is in the neutral range with slightly acidic. The results also indicate a reading at $\mathrm{pH} 7$ and above. The differences in reading is observed due to weather changing which in rainy or sunny days. It was studied that that weather has obviously effects to water $\mathrm{pH}$ level. Acid rain is comprehensively acknowledged to be accountable for acidifying soil and water in particular area, mostly in urban area [12]. The rain that fell on soil was mix with fertilizer and then flow down to the lake. This mixture are acidic, is then mix together with the water hence, may turns the water slightly acidic. Meanwhile, there were differences reading by $7 \mathrm{mg} / 1$ using offline and online approaches for tss measurement. It was studied that the rain gave an impact on water turbidity especially during heavy rain. It was found that rain events of the early rainy season through mid-tempestuous season are conclusive in initiating turbidity increment [13]. The rain transported the sediment into the water and turns the water murky hence increasing the tss.

The results collected can be summarized to average $\mathrm{pH}$ of 6.85 and tss of $50 \mathrm{mg} / \mathrm{l}$; which reflect to class II of WQI (refer Table 1). According to WQI, the IIA needs a conventional water treatment if it uses as a water supply, while IIB is suitable for water recreational used body contact.

\section{CONCLUSION}

The project aims to develop a smart system to monitor the water quality level based on Water Quality Index (WQI) as a standard practice by Department of Environment (DOE) Malaysia. The developed system was successfully detect both $\mathrm{pH}$ and turbidity levels hence updating in Wix IoT platform. Overall, the system developed offers fast and easy monitoring of $\mathrm{pH}$ and turbidity level in ensuring clean water is continuously maintained. Based on the results obtained, the water level of "Tasik UTeM" can be classified into class IIB which is suitable for water recreational used body contact. However, the presented work was just concern on the physical water parameters hence further extend to chemical parameter for verifying a better result in measuring the WQI value.

\section{ACKNOWLEDGEMENTS}

This research work is fully supported by PJP/2016/FKEKK-CETRI/S01494. The authors fully acknowledged Ministry of Higher Education (MOHE) and Universiti Teknikal Malaysia Melaka (UTeM) for the approved fund and support which makes this important research viable and effective. 


\section{REFERENCES}

[1] R. Nithyanandam, T. W. Huan and N. H. T. Thy, "Case Studies: Analysis of Water Quality in Sungai Batu Ferringhi," Journal of Engineering Science and Technology, EURECA 2014 Special Issue, pp. 15 - 25, April 2015.

[2] A. S. Rao, et al., "Design of Low-cost Autonomous Water Quality Monitoring System," in International Conference on Advances in Computing, Communications and Informatics (ICACCI), 2013.

[3] http://www.wepa-db.net/policies/law/malaysia/eq surface.htm

[4] Z. Wang, Q. Wang, X. Hao, “The design of the remote water quality monitoring system based on WSN," in 2009 5th International Conference on Wireless Communications, Networking and Mobile Computing, 2009. pp. 1-4.

[5] P. Jiang, et al., "Design of a water environment monitoring system based on wireless sensor networks," Sensors, vol. 9, pp. 6411-6434, 2009.

[6] A. G. da S. Junior, et al., "Towards a Real-Time Embedded System for Water Monitoring Installed in a Robotic Sailboat," Sensors, vol. 16(8), 1226, 2016.

[7] N. A. Cloete, R. M. Malekian and L. Nair. "Design of Smart Sensors for Real-Time Water Quality Monitoring," IEEE Access, vol 4, pp. 3975-3990, July 2016.

[8] MD. R. Ranjbar, A. Abdalla, "Development of an Autonomous Remote Access Water Quality Monitoring System,” Indonesian Journal of Electrical Engineering and Computer Science, vol. 8(2), , pp. 467- 474, 2017.

[9] Y. Wu, et al., "Water Quality Evaluation Model Based on Hybrid PSOBP Neural Network Information engineering college,” TELKOMNIKA Indonesian Journal of Electrical Engineering, vol.12(2), pp. 1495-1501, 2014.

[10] X. Wang and P. Xu, "Deployment of TinyOS for Online Water Sensing," TELKOMNIKA Indonesian Journal of Electrical Engineering, vol.12(6), pp. 4802 - 4807, 2014.

[11] E. C. Krug and C. R. Frink, "Acid Rain on Acid Soil: A New Perspective”, Science, vol 221(4610), 1983.

[12] E. Robert, et al., "Monitoring water turbidity and surface suspended sedimentconcentration of the Bagre Reservoir (Burkina Faso) using MODIS and field reflectance data," International Journal of Applied Earth Observation and Geoinformation, vol 52, pp. 243-251, October 2016.

\section{BIOGRAPHIES OF AUTHORS}
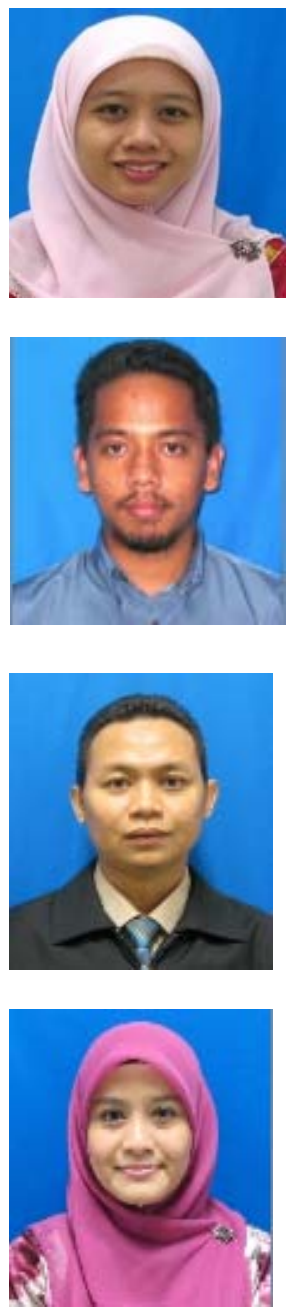

Sharatul Izah Samsudin graduated for her his first degree in B.Eng (Electronic Engineering) at Universiti Sains Malaysia (USM). Following that, she obtained her M.Eng. and $\mathrm{PhD}$ from Universiti Teknologi Malaysia (UTM). She specializes on control system modeling with interest in water quality control environment and IoT applications. She is currently working as a senior lecturer in the Industrial Electronic Department, Faculty of Electronic and Computer Engineering, UTeM

Sani Irwan Md Salim obtained his first degree in B.Eng (Electronic Engineering), from the Universiti Teknologi Malaysia (UTM), in 2002. Following that, he obtained his M.EngSc (Computer \& Communication) from Queensland University of Technology (QUT), Australia. He is currently working as senior lecturer in the Computer Engineering Department, Faculty of Electronic and Computer Engineering, UTeM. His main research area is in reconfigurable computing with interest in FPGA applications.

Khairuddin Osman received B. Eng. in Electronics Engineering (Industrial Electronics) from Universiti Teknikal Malaysi and M. Eng. in Electrical Engineering (Electrical - Mechatronics and Automatic Control) from Universiti Teknologi Malaysia. In 2014, he completed Ph.D. degree in Electrical Engineering from Universiti Teknologi Malaysia. He is currently a senior lecturer at the Faculty of Electronics and Computer Engineering, Universiti Teknikal Malaysia Melaka, Malaysia. His interests are in mechatronics, embedded system, pneumatic actuator, industrial electronics, and robotics.

Siti Fatimah Sulaiman received B. Eng. (Industrial Electronics) from Universiti Teknikal Malaysia Melaka in 2009 and M. Eng. (Electrical - Mechatronics and Automatic Control) from Universiti Teknologi Malaysia in 2012. She is currently pursuing Ph.D. degree in Electrical Engineering at Universiti Teknologi Malaysia. Her main research interest is in the field of control system design, system identification, mechatronics, automation, and instrumentation. 